Viso - Cadernos de estética aplicada Revista eletrônica de estética

ISSN 1981-4062

$N^{\circ} 15,2014$

http://www.revistaviso.com.br/

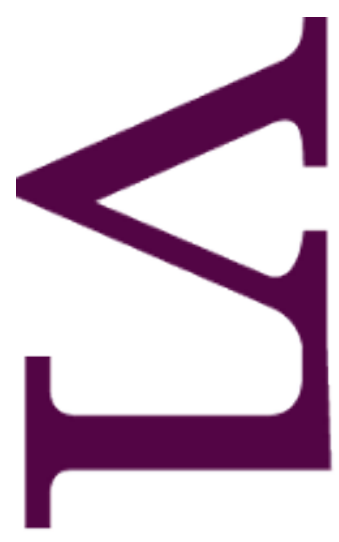

ᄂ

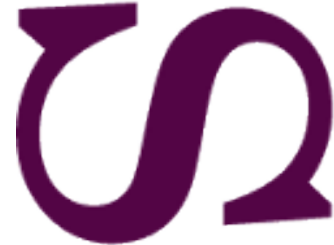

$\varangle$

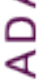

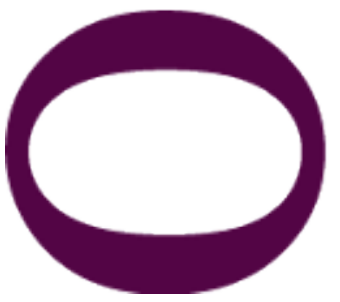

\title{
Pina 3D e a força sensível do cinema
}

Vladimir Vieira 


\section{RESUMO}

\section{Pina 3D e a força sensível do cinema}

Esse artigo discute a força sensivel do cinema a partir de uma análise do documentário Pina 3D, de Win Wenders, sobre a coreógrafa Pina Bausch. Sugiro, inicialmente, que a questão acerca do status ontológico das imagens no cinema é central para a obra de Wenders desde que o cineasta conquistou o Leão de Ouro em Veneza com o filme $O$ estado das coisas, em 1982. Em seguida, discuto a possibilidade de compreender as imagens cinematográficas como um desafio ao debate acerca da representação tal como ele se desenvolveu no período inicial da filosofia moderna: por um lado, elas são criadas arbitrariamente, tais como aquelas que são produzidas pelo uso da imaginação; por outro, assemelham-se aos dados sensíveis mais fortes e involuntários que tomamos ordinariamente como cópias das coisas tais como existem no mundo fora da mente. Nesse sentido, poder-se-ia dizer, em termos humeanos, que tais imagens contém propriedades tanto de ideias da imaginação quanto de impressões dos sentidos. Por fim, argumento que o emprego da tecnologia $3 \mathrm{D}$ em Pina representa um ataque ao paradigma representacional no cinema, na medida em que o filme de Wenders pressupõe que o cinema obtém a sua qualidade estética não do fato de copiar a "realidade", mas antes da força sensível das próprias imagens.

Palavras-chave: Wim Wenders - Pina Bausch - ontologia da imagem - filosofia moderna 


\section{ABSTRACT}

\section{Pina 3D and the Sensible Power of Movies}

In this paper, I examine the sensible power of movie images based on an analysis of Pina 3D (2011), Wim Wenders' documentary feature on choreographer Pina Bausch. At first I suggest that the question about the ontological status of images in films is a central issue of Wender's work that goes back to his 1982 Golden Palm in the Cannes Film Festival with The State of Things. From this initial statement, I argue that movie images defy traditional philosophical discussions of representation, such as were common in the early Modern period: on the one hand, they are arbitrarily created, like those produced by our imagination; on the other hand, they resemble the more powerful, involuntary sensory data that we ordinarily regard as copies of things that exist in the world outside our minds. In Humean terms, we could say that movie images mix qualities both of ideas of imagination and of impressions of the senses. Finally, I propose that the use of 3D technology in Pina may be understood as an attack on the representational paradigm in cinema, since it points out to the assertion that movies retain their aesthetic force not from the fact that they may be taken as copies of "real" things, but rather from the sensible power of the images themselves.

Keywords: Wim Wenders - Pina Bausch - ontology of film - early Modern philosophy 


\section{VIEIRA, V. "Pina 3D e a força sensível do cinema". In: Viso: Cadernos de estética aplicada, v. VIII, n. 15 (jan- dez/2014), pp. 35-46.}

DOI: 10.22409/1981-4062/v15i/172

Aprovado: 26.10.2014. Publicado: 31.01.2015.

(c) 2014 Vladimir Vieira. Esse documento é distribuído nos termos da licença Creative Commons Atribuição-NãoComercial 4.0 Internacional (CC-BY-NC), que permite, exceto para fins comerciais, copiar e redistribuir o material em qualquer formato ou meio, bem como remixá-lo, transformá-lo ou criar a partir dele, desde que seja dado o devido crédito e indicada a licença sob a qual ele foi originalmente publicado.

Licença: http://creativecommons.org/licenses/by-nc/4.0/deed.pt BR

Accepted: 26.10.2014. Published: 31.01.2015.

(C) 2014 Vladimir Vieira. This document is distributed under the terms of a Creative Commons Attribution-NonCommercial 4.0 International license (CC-BY-NC) which allows, except for commercial purposes, to copy and redistribute the material in any medium or format and to remix, transform, and build upon the material, provided the original work is properly cited and states its license.

License: http://creativecommons.org/licenses/by-nc/4.0/ 
O estado das coisas, vencedor do Leão de Ouro em Veneza em 1982, contém talvez uma das falas mais célebres de toda a obra cinematográfica de Wim Wenders. Ela é enunciada por Joe, câmera da equipe de filmagem que vaga entediada pela praias de Portugal aguardando novos aportes financeiros dos patrocinadores que, entretanto, nunca chegam. A personagem, interpretada pelo cineasta Samuel Fuller, diz o seguinte: "A vida é em cores, mas o preto e branco é mais realista".

Nos anos de 1980, essa afirmação era usualmente interpretada como uma bravata polêmica direcionada contra a indústria de entretenimento, que privilegia o uso de películas coloridas. No final de $\mathrm{O}$ estado das coisas, com efeito, o diretor Friedrich viaja a Los Angeles e descobre que os investidores - na verdade, mafiosos - haviam perdido o interesse em seu filme justamente quando descobriram que ele estava sendo rodado em preto e branco. A obra de Wenders conclui-se com um tiroteio em que Friedrich, emblematicamente, empunha sua filmadora como se estivesse segurando uma arma.

Passados quase trinta anos, a fala de Joe, compreendida nesse sentido, parece no melhor dos casos ter perdido integralmente a sua força originária e, no pior, constituir-se como indício de desonestidade intelectual. Desde então, Wenders filmou repetidamente em cores, e teve à sua disposição orçamentos milionários e atores indiscutivelmente ligados à indústria de entretenimento, tais como Andie MacDowell, Mel Gibson ou Mila Jovovich. Creio, entretanto, que ela ainda denota, de modo mais profundo, um elemento central de suas preocupações artísticas - as quais vieram à tona, de modo exemplar, em seu recente trabalho sobre a coreógrafa Pina Bausch.

Antes de tratarmos de Pina (2011), entretanto, é necessário entender o que há de polêmico na afirmação de Joe. Recorro ao quadro conceitual da filosofia moderna, que me é mais familiar, para colocar esse problema: a estranheza que ela intuitivamente nos causa tem sua origem no fato de que o modelo que empregamos para interpretar as imagens do cinema é o das nossas próprias imagens mentais, as quais possuem cor. Uma vez que admitimos também, cotidianamente, que elas são representações ou cópias fidedignas da realidade, sugerir que o preto e branco é mais "real" parece um contrassenso.

À época em que $O$ estado das coisas foi premiado em Veneza, tal sugestão estava ligada a uma agenda política de contraposição a uma concepção eminentemente representativa da arte, particularmente dominante na indústria cinematográfica. Ouso dizer que, na verdade, pouco se alterou durante esse período, e as formas narrativas tradicionais ainda presidem nossa relação com o cinema. Questões a respeito de o que as imagens objetivamente denotam são recorrentes na experiência de assistir a um filme - ou, ao menos, a respeito de o que seu encadeamento "significa", daquilo que o diretor teria pretendido "comunicar".

O que prende, entretanto, o cinema de modo tão firme à sua função representativa, 
malgrado o combate travado contra ela em $O$ estado das coisas e em outras tantas obras de iconoclastas da sétima arte ao longo do século XX? A analogia com as imagens mentais sugere um caminho para responder a essa questão. E pretendo efetivamente servir-me aqui das observações de filósofos do período inicial da filosofia moderna talvez um dos que se entregaram com mais afinco à análise de tais representações.

Diversos autores dos séculos XVI e XVII reconhecem dois tipos de entidades mentais, que se diferenciam de duas maneiras: pela intensidade com que se manifestam no espírito e por sua origem. Descartes, por exemplo, aborda esse problema ao buscar, na terceira de suas Meditações metafísicas, uma classificação para os diferentes tipos de ideias com vistas a fundamentar a primeira prova da existência de Deus: "que eu ouça um som, que eu veja o sol, que eu sinta o fogo", afirma ele "até aqui julguei que isso procedia de certas coisas situadas fora de mim; e, enfim, as sereias, os hipogrifos e coisas semelhantes são forjadas por mim mesmo".' Uma diferença fundamental entre essas duas espécies de representações é que as primeiras "não dependem da minha vontade, nem por conseguinte de mim mesmo, pois se oferecem frequentemente mesmo à minha revelia - quer queira, quer não, sinto o calor [...]". ${ }^{2}$ Sem referir-se a objetos externos, Berkeley estabelece, no Tratado acerca dos princípios do conhecimento humano, uma distinção semelhante:

Descubro poder despertar ideias em minha mente à vontade [...]. Mas qualquer que seja o poder que detenho sobre meu próprio pensamento, descubro que as ideias efetivamente percebidas pelos sentidos não têm semelhante dependência de minha vontade. [...] As ideias dos sentidos são mais fortes, vivazes e distintas do que aquelas da imaginação. Elas possuem igualmente uma constância, ordem e coerência, e não são despertadas a esmo, tais como o são aquelas que são o efeito de vontades humanas, mas em uma sequência ou série regular [...]. ${ }^{3}$

Coube provavelmente a Hume a formulação mais sistemática para essa questão. Segundo o filósofo, todas as nossas entidades mentais - nossas percepções - dividemse em dois tipos, ideias e impressões, e a diferença entre elas "consiste nos graus de força e vivacidade com que atingem a mente e abrem caminho até nosso pensamento ou consciência". ${ }^{4}$ Ideias são cópias de impressões sensíveis que as precederam e, desse modo, "as suas imagens fracas no pensamento e raciocínio". ${ }^{5}$ Elas podem ser produzidas arbitrariamente por meio da imaginação ou da memória, ao passo que as impressões simplesmente se dão espontaneamente ao sujeito, a partir de origens desconhecidas.

A invenção da fotografia - e, por derivação, do cinema - agregou significativa complexidade a essas análises. As imagens fotográficas possuem mais vivacidade do que quaisquer ideias, para empregarmos a terminologia de Hume, praticamente atingindo o grau de intensidade característico de nossas impressões. Ao contrário destas, entretanto, temos consciência de que se trata de representações artificiais, produzidas por nós, como as ideias. 
Creio que é essa força sensível aquilo que impõe, de modo mais fundamental, a imediata associação entre as imagens do cinema e nossas impressões, e que torna tão difícil superar o paradigma representativo nessa arte. A indústria de entretenimento, nesse sentido, nada mais faz do que explorar uma característica intrínseca a esse tipo de representação. Sua história mostra, na verdade, a crescente mobilização de recursos tecnológicos com o intuito de torná-la ainda mais vivaz e mais análoga ao seu correspondente mental - com a introdução do som, da cor, e, mais recentemente, da profundidade, graças à difusão da filmagem em terceira dimensão. Entre esses recursos encontra-se, também, a malograda tentativa de emular mesmo as sensações olfativas por meio do dispositivo denominado "odorama".

O que essas observações têm em vista é, em última análise, que a imagem fotográfica está indissociavelmente ligada a um certo realismo: o que elas apresentam é aquilo que constitui a nossa experiência cotidiana do mundo. A partir de um ponto de vista bastante diferente daquele que me proponho a seguir aqui, essa proposição constitui um dos elementos mais fundamentais de The World Viewed (1971), obra seminal de Stanley Cavell acerca de uma possível ontologia do cinema. Como sugere o autor em "More of The World Viewed", ensaio publicado em 1979 onde discute criticamente alguns aspectos de seu livro, "[..] o filme mantém uma relação com a realidade sem precedentes nas outras artes". ${ }^{6}$

Em The World Viewed, a natureza de tal relação é determinada através da fórmula segundo a qual a base material ou física de um filme constitui-se de "sucessões de projeções automáticas de mundo". ${ }^{7}$ Explorar em detalhe o que, exatamente, é projetado na tela seria uma tarefa complexa demais para os limites do presente trabalho. É suficiente mencionar que as análises de Cavell tomam por base o célebre ensaio de Baudelaire, O pintor da vida moderna, para identificar os três grandes mitos instaurados pela experiência do cinema clássico hollywoodiano: o dandi, a mulher e o homem militar. ${ }^{8}$ O autor argumenta, posteriormente, que o desenvolvimento do filme "modernista", na segunda metade do século XX, corresponde precisamente à decadência dessa dimensão mítica, ou seja, à perda da "convicção nos mitos e gênios originários do filme o mundo público dos homens, a companhia privada da mulher, o isolamento secreto do dandi $[. . .]^{\prime \prime}$ - o que se poderia compreender, do ponto de vista filosófico, a partir do estranhamento frente ao mundo que se costuma atribuir à condição humana na contemporaneidade. ${ }^{10}$

Mais do que aquilo que é projetado, é importante para meus propósitos discutir a forma como se dá a projeção no cinema, a saber, automaticamente. Como reconhece Cavell no capítulo que consagra especificamente à abordagem desse tema, a noção de automatismo ganha diversos significados em The World Viewed. Ela denota, por exemplo, os modos segundo os quais se pode produzir os objetos pertinentes a uma certa tradição artística. ${ }^{11}$ Creio, entretanto, que esses diferentes desdobramentos do conceito articulam-se a uma observação fundamental acerca da fotografia e de seu uso 
no cinema: o homem permanece ausente tanto no registro da imagem quanto em sua projeção na tela. Segundo Cavell, '“automático' enfatiza o fato mecânico da fotografia, em particular, a ausência da mão humana na formação desses objetos e ausência de suas criaturas em sua projeção". ${ }^{12}$ Ao contrário do que se dá na pintura, o registro fotográfico ocorre mecanicamente, por meio de um aparato; e, ao contrário do que se dá no teatro, sua experiência é simultaneamente a experiência de uma realidade e a experiência de nossa ausência da realidade que é o objeto dessa experiência.

O fato de que a experiência do cinema é uma experiência da realidade decorre, ademais, de características pertinentes à própria imagem fotográfica. Como aponta Cavell, uma fotografia não copia ou se assemelha àquilo de que é uma representação, mas antes o apresenta. Ao contemplá-la, podemos sempre nos perguntar o que estaria ao lado daquilo que temos diante de nós, ou seja, o que da realidade foi deixado de lado naquele recorte específico de mundo que constitui o objeto da apresentação. Por isso se poderia dizer: "uma pintura é um mundo; uma fotografia é do mundo". ${ }^{13}$

É esse realismo que Cavell atribui à imagem fotográfica aquilo que, em última análise, procurei estabelecer recorrendo à noção humeana de vivacidade. Mas em que consiste, exatamente, a realidade que a fotografia e o cinema apresentam?

Retomando a analogia com as entidades mentais, podemos colocar essa questão nos termos da filosofia moderna, e nos perguntar: a vivacidade das impressões é suficiente para conferir "realidade" a essas representações, se entendemos essa palavra designando correspondência a algo diferente da própria imagem mental? Em suas Meditações, Descartes responde negativamente, ao reconhecer que "ainda que essas ideias não dependam de minha vontade, não está daí estabelecido que elas procedam necessariamente de coisas situadas fora de mim. Com efeito, [...] talvez haja também uma outra faculdade qualquer em mim, produtora dessas ideias, que ainda não me seja suficientemente conhecida [...]". ${ }^{14}$ Berkeley levanta inúmeros argumentos contra essa hipótese - a qual, com efeito, pretendia refutar - e conclui que o que chamamos de realidade não é, em última análise, a suposta adequação de nossas representações a objetos externos, mas sim as duas características que distinguem as ideias dos sentidos das demais: sua vivacidade e o fato de que são produzidas à revelia de nossa vontade. ${ }^{15}$

Se é assim, a realidade do cinema, assim como a das imagens mentais, não pode ser definida em termos representacionais, mas antes, talvez, apresentacionais. O que torna reais as imagens cinematográficas é sua força e vivacidade sensíveis. Sob esse ponto de vista, a afirmação de Joe em $O$ estado das coisas não parece tão surpreendente: o preto e branco pode ser tão ou mais vivaz do que a cor.

Creio que a preocupação de Wenders com o status ontológico da imagem cinematográfica foi confirmada recentemente em Pina, que o diretor insistentemente classificou, em entrevistas, como um projeto coautoral. O aspecto mais fundamental para 
a experiência desse filme é a tecnologia 3D - tão fundamental que todas as questões que ele coloca perdem completamente o seu significado na ausência desse elemento. Como indiquei mais acima, o emprego dessa técnica de filmagem secular teria por objetivo tornar as imagens fotográficas mais "reais", emulando a experiência de profundidade que o olho humano vivencia. Ocorre, entretanto, que na verdade não vemos como vê a câmera em 3D. Se nossas impressões mentais parecem, de fato, mais profundas do que seu correspondente na película tradicional, elas não destacam elementos em primeiro plano deixando outros, ainda nítidos, totalmente presentes no fundo; nem apresentam constantemente à nossa percepção objetos que parecem saltar em direção a nós.

Quero dizer, assim, que o cinema 3D é em última análise ainda mais real do que nossas impressões, no sentido em que Berkeley designa o que é realidade. É sintomática, nesse sentido, a predileção da indústria cinematográfica por seu emprego em filmes com argumento fantástico, tais como thrillers e ficção científica, onde essa característica permanece oculta pela própria natureza do enredo. Ao contrário, a escolha de um tema muito mais prosaico - o trabalho de uma companhia de dança contemporânea - chama a atenção para a diferença entre essas imagens e as representações mentais que elas supostamente emulariam.

Mais ainda, para produzir o efeito a que se propõe, a imagem 3D precisa selecionar cuidadosamente que elementos serão destacados e quais ficarão em segundo plano. Não é fortuito, por exemplo, que o espectador se assuste com a possibilidade de ser atingido pela água durante a coreografia de Vollmond. Isso decorre de uma decisão consciente de Wenders, do mesmo modo que a faca ensanguentada em exemplos menos nobres do gênero.

É um erro, portanto, imaginar que Pina proporciona ao espectador uma experiência próxima à daquele que se familiarizou com o trabalho de Pina Bausch em um teatro. De nenhum ponto da plateia, do palco ou da coxia seria possível ver o que o filme mostra. Nunca o vestido vermelho de $A$ sagração da primavera fora apreendido por qualquer olho humano como na obra de Wenders. Tivesse a oportunidade de assisti-la, a própria coreógrafa seria forçada a reconhecer que estava vendo algo que nunca vira antes. $\mathrm{O}$ que se dá à nossa percepção não é, portanto, a realidade da dança de Bausch, mas a realidade que o diretor constrói a partir dela. Trata-se, efetivamente, de um trabalho de co-autoria.

Como se vê, é possível estabelecer uma continuidade entre as preocupações de Wenders em 1982 e 2011. O que está em jogo é perguntar-se sobre aquilo que confere realidade às imagens cinematográficas. Creio que o modo como o problema é formulado, nesses dois momentos, tem em vista ressaltar que o real do cinema é resultado da própria força sensível das imagens, e não do fato de que representam algo externo a elas: em $O$ estado das coisas, porque as representações deveriam parecer menos reais, 
em Pina, porque são efetivamente mais reais do que a realidade da experiência proporcionada por nossas imagens mentais.

Resta ainda uma questão que esse artigo não aborda em profundidade e que só posso, nesse momento, mencionar de passagem. $O$ que exatamente confere às imagens cinematográficas suficiente vivacidade para torná-las reais? À primeira vista, pareceria evidente sugerir que se trata dos próprios dados sensíveis, ao fazerem-nas semelhantes às nossas imagens mentais. $\mathrm{E}$, em certa medida, isso parece correto: por exemplo, o fato de que no cinema elas se movem é certamente uma condição necessária para que sua percepção surja para nós como análoga àquela de nossa experiência ordinária do mundo. ${ }^{16}$

Por outro lado, os dados sensíveis, por si mesmos, não podem explicar inteiramente a realidade do cinema, pois a sua ausência nem sempre torna um filme menos real. Outro elemento parece estar em jogo aqui, ao qual fiz apenas breves alusões nesse trabalho. Ele diz respeito ao fato de que, embora se assemelhe à imagem mental com relação ao grau de vivacidade, a fotografia é um tipo de representação criado arbitrariamente pelo engenho humano. Na experiência da realidade cotidiana, podemos deslocar os olhos e verificar o que está ao lado daquilo que temos diante a nós; na experiência da realidade fotográfica, só podemos experimentar aquilo que é apresentado para nós como realidade.

Quero dizer com isso que a experiência do cinema me parece indissociável da percepção de que a realidade apresentada através da força sensível de suas imagens é uma realidade construída. É irrelevante aqui se supomos que a construção é produto da autoria de um diretor ou, ao contrário, da ausência de autoria que caracterizaria os meios de produção da indústria do entretenimento. Mas não é irrelevante que, ao experimentar a realidade cinematográfica, se possa sempre perguntar por que ela foi construída desse modo, e não de outro.

Essa é possivelmente uma das direções em que minha compreensão da natureza da fotografia se afasta daquela exposta em The World Viewed. A insistência de Cavell no caráter automático do registro fotográfico parece minimizar o papel daquele que enquadra e decide o que enquadrar, como se a arbitrariedade da produção imagética implicasse necessariamente a suposição de um irrealismo cinematográfico. ${ }^{17} \mathrm{De}$ acordo com o exposto acima, entretanto, as imagens obtêm realidade de sua força sensível, trate-se de imagens mentais ou de imagens produzidas pelo homem. É justamente esse estranho paradoxo que, em minha opinião, qualifica mais propriamente a experiência do cinema: a apresentação arbitrária da realidade. Nesse sentido, ele talvez seja o que mais se aproxime daquilo que Kant esperava da bela arte: parecer natureza, sem deixar de ser arte. ${ }^{18}$ 


\section{* Vladimir Vieira é professor adjunto do Departamento de Filosofia da UFF.}

* Sou muito grato às considerações críticas a este texto feitas por Joe Kickasola, Patrick Pessoa e Márcia Gonçalves quando foi apresentado no VII Encontro Nacional do GT de Estética da ANPOF e na International Lisbon Conference on Philosophy and Film, ambos realizados no primeiro semestre de 2014.

${ }^{1}$ DESCARTES, R. Méditations métaphysiques. Edição de Michelle Beyssade. Paris: LGF, 1990, pp. 93-95.

2 Ibidem, p. 95.

${ }^{3}$ BERKELEY, G. Philosophical Writings. Edição de Desmond M. Clarke. Cambridge: Cambridge University, 2008, p. 94.

${ }^{4}$ HUME, D. A Treatise of Human Nature. Edição organizada por David Fate Norton e Mary J. Norton. Oxford, Clarendon, 2007, p. 7.

${ }^{5}$ Ibidem.

${ }^{6}$ CAVELL, S. The World Viewed. Harvard: Harvard University, 1979, p. 166.

${ }^{7}$ Ibidem, p. 105.

8 "Esses, do modo como Baudelaire os descreve, não são simplesmente itens adicionais para o sustento diário do cinema: eles são os gênios que presidem os filmes" (Ibidem, p. 47). Cavell discute o conteúdo desses três mitos nos capítulos 8 e 9 de seu livro.

9 Ibidem, p. 62.

${ }^{10}$ Como sugere Cavell (p. 60), ao entrar no "modernismo" os filmes "não estabelecem mais de modo natural a convicção em nosso estar presente no mundo".

${ }^{11}$ Cf. Ibidem, pp. 104-105ff.

12 Ibidem, p. 73. Essa fórmula, que ocorre no capítulo 11, sumariza as discussões propostas nos capítulos 2 e 3 de The World Viewed.

${ }^{13}$ Ibidem, p. 24.

${ }^{14}$ DESCARTES, R. Op. cit., pp. 97-99.

${ }^{15}$ A posição de Berkeley nos Princípios é a de que não existe substância material. O filósofo levanta argumentos contra a noção de matéria ao longo dos 23 primeiros parágrafos de sua obra e, posteriormente, procura igualmente defender-se de ataques que poderiam ser direcionados à sua doutrina, nos §§34-84. O primeiro consiste, precisamente, na suposição de que o imaterialismo implicaria a destruição da realidade, pois ideias existem apenas na mente e não são, portanto, "reais". Berkeley responde a essa objeção do seguinte modo: "Não levanto argumentos contra a existência de qualquer que podemos apreender, seja pelos sentidos ou pela reflexão. Não há qualquer questão de que as coisas que vejo com meus olhos e toco com minhas mãos efetivamente existem. A única coisa cuja existência negamos é aquilo que os filósofos chamam de matéria ou substância corpórea. [...] Há substâncias espirituais, mentes ou almas humanas, que desejam ou despertam ideias em si mesmas à vontade; mas elas são tênues, fracas e inconstantes com relação às outras que percebo pelos sentidos, as quais, sendo impressas nos espíritos de acordo com certas regras ou leis da natureza, mostram-se o efeito de uma mente mais poderosa e sábia do que os espíritos humanos. Diz-se que essas últimas possuem nelas mais realidade do que as primeiras, o que quer dizer que elas nos afetam mais, são mais ordenadas e distintas, e que não são ficções das mentes que as percebe. E, nesse sentido, o sol que vejo de dia é o sol real, e o sol que imagino à noite uma ideia do anterior. No sentido aqui dado de 'realidade', é evidente que todo vegetal, estrela, mineral, e em geral cada parte do sistema mundano é um ente tão real segundo nosso princípios quanto segundo qualquer outro". 
${ }^{16}$ Cavell dá grande importância ao surgimento das imagens em movimento como uma condição para tornar os filmes capazes de apresentar a realidade: "colocar imagens mecanicamente em movimento superou o que chamei anteriormente de teatralidade inerente à fotografia (parada)" (Op. cit., p. 119).

17 Em sua obra mais célebre sobre o tema (Filosofia da caixa preta. Rio de Janeiro: Sinergia Relume Dumará, 2009), Vilém Flusser critica com veemência a atribuição de um automatismo mecânico à fotografia que se sobreponha ao papel do fotógrafo para a produção de tais imagens. "Vistas ingenuamente", afirma, elas "significam cenas que se imprimiram automaticamente sobre superfícies. Mesmo um observador ingênuo admitiria que cenas se imprimiram a partir de um determinado ponto de vista. Mas o argumento não lhe convém. O fato relevante para ele é que as fotografias abrem ao observador visões de mundo. Toda filosofia da fotografia não passa, para ele, de ginástica mental para alienados" (p. 37). Mas os elementos da imagem fotográfica não são, para o filósofo, meras impressões do mundo, mas antes "conceitos transcodificados que pretendem ser impressões automáticas do mundo. Tal pretensão precisa ser decifrada por quem quiser receber a verdadeira mensagem das fotografias: conceitos programados. Destarte, o observador ingênuo se vê obrigado, malgré lui, a mergulhar no torvelinho das reflexões filosóficas que procurou eliminar, por considerá-las ginástica mental alienada" (p. 40, grifo meu). Mais ainda, o processo que leva à transcodificação de tais conceitos envolve o aparelho e o fotógrafo - ou, segundo a expressão do autor, o "complexo 'aparelho-fotógrafo" (p. 41) - em uma relação que é frequentemente caracterizada como uma combinação de colaboração e combate: "Se compararmos as intenções do fotógrafo e do aparelho, constataremos pontos de convergência e divergência. Nos pontos convergentes, aparelho e fotógrafo colaboram; nos divergentes, se combatem. Toda fotografia é resultado de tal colaboração e combate" (p. 42). Compreender o significado de uma fotografia implica, desse modo, perguntar-se: "até que ponto conseguiu o fotógrafo apropriar-se da intenção do aparelho e submetê-la à sua própria? [...] Até que ponto conseguiu o aparelho apropriar-se da intenção do fotógrafo e desviá-la para os propósitos nele programados? [...] As fotografias 'melhores' seriam aquelas que evidenciam a vitória da intenção do fotógrafo sobre o aparelho: a vitória do homem sobre o aparelho” (p. 42).

18 "A arte só pode ser chamada bela quando estamos conscientes de que é arte e, entretanto, parece a nós natureza". KANT, I. Kritik der Urteilskraft. Frankfurt am Main: Suhrkamp, 1976, p. 241. 